\title{
Research on Transmission and Influence of Mainstream Media from the Perspective of Network Public Opinions
}

\author{
Fang Zhang \\ Xi'an Peihua University, Xi’an, 710125, China \\ email
}

Keywords: Transmission and influence, Mainstream media, Network public opinions

\begin{abstract}
In the current society, the network opinion has changed the transmission process, weakened the credibility of the mainstream media, making the public opinion environment increasingly complex. The transmission and influence of mainstream media become a big issue of common concern of the whole society. In view of the above problems, this paper puts forward the suggestions of strengthening responsibility sense, grabbing time window and building brand column to provide some references for the relative researchers.
\end{abstract}

\section{Introduction}

The concept of the mainstream media with the prosperity of mass media have gradually paid attention to. The core of the mainstream media is to guide and maintain the mainstream values of society, other media can only operate within the framework of the mainstream media. In the transformation of society, economy, environment and culture, ideology, the main tool of mainstream media as a social value system construction, should assume social value guidance, the basic mission of cultural heritage, shaping the concept, the breadth and depth of social objective and fair coverage of promoting the harmonious development of society. With the rapid development of mainstream media, every ordinary people can use the Internet to express their opinions, which is characterized by low threshold, simple operation and strong interactive ability. Because of its convenient advantages and rapid development in the new media era, and the traditional media has caused a lot of impact. Media is a force of integration, promotion and execution. The essence of communication is a kind of promotion, different media, even if the audience has the same, the effect is not the same. The core of mass media communication ability is the ability of media communication, that is, the ability of the media to reach the audience and produce effect. The ability to reach the audience can be reflected by audience rating, reading ability, arrival rate, circulation and other indicators. But the society is full of false, fuzzy and false information every day, which may lead to false public opinion. If the media provides true and sufficient information, it will reduce the misunderstanding of public opinion and social psychological shock. The mainstream media is the main body of the communication system, which plays a very important role in the guidance of public opinion and the promotion of social development. Under the new media environment, presents a new media platform on the pattern of interests is becoming more and more complicated, the ideological tendency of pluralism, the pursuit of value increasingly complicated, spreading the social mainstream value was gradually weakened to some extent. In this situation, the mainstream media must grasp the right to speak through their own efforts.

2. Challenges Faced with Mainstream Media from the Perspective of Network Public Opinions

\subsection{Changed Transmission Process}

The formation mechanism of public opinion has undergone profound changes, the dominance of 
the traditional media agenda setting is shaken, the mainstream media influence decline of traditional media, Internet, mobile phone and other new media pluralism, the mechanism of public opinion generated a profound change. While the formation mechanism of public opinion has undergone profound changes, the media in fact formed a multi-level structure, the emergence of the mainstream media public opinion field, network public opinion field, mobile phone public opinion field and oral public opinion field. The field of network media and mobile phone media field the verbal field of public opinion topic on Street Lane integration, amplification, so that the two field of public opinion topic closer to life, more freedom, more real, attractive and influential than the mainstream media field. Its ability to guide public opinion should not be underestimated, has gradually shown the impact trend of mainstream media field. From the change of public opinion formation mechanism and the structure of the public opinion is not difficult to see that the monopoly of the mainstream media agenda setting has been shaken, the network media agenda ahead of traditional media agenda to guide the new trend of the concern of public opinion. Traditional media is a one-way communication, point-to-point communication, and the audience can only passively accept. The new media is interactive communication, point to face communication, the audience can receive information, but also ask questions, verify, discuss, re spread, and all Internet users can see if you want to see. Compared with the traditional media Co. layout and limited time to network information. With the popularity of the network, almost anywhere can access the Internet, especially the mobile client, so that a small mobile phone can carry, access to the Internet anytime. The network fee is far lower than the fees for the use of newspaper subscriptions and cable TV, these changes caused by technology progress, the traditional media can only adapt to the unstoppable. In such a situation, the use rate of mainstream media is decreasing, and the influence of mainstream media is declining.

\subsection{Weaken Public Trust}

Authority and credibility are the most essential attributes and brands of the mainstream media, which are given by the basic political system of our country. But as the mouthpiece of the party and the sounder in the mainstream media, the term spread in face of stiff, stiff voice, communication means a single, although these years of continuous change in voice, adjust posture, but the inherent mode of the audience on the mainstream media forms for a long time in a short period of time, it is difficult to change. Some audience would rather believe that a post on the network, is not willing to believe both the spread of mainstream media. The mainstream media in publicity and other aspects of the audience, the report timeliness, information content of demand and there is not a small distance, especially in the operation of aphasia and major events and hot events on the mistakes, and even some of the audience with emotions of the mainstream media, the mainstream media publicity without trust sense, not to mention the interaction and emotional resonance. Power. The credibility of the party and the government is isomorphic with and supported by the credibility of the mainstream media and the transmission and influence of the mainstream ideas and public opinion. Some improper acts of some Party organizations, government departments and individual leading cadres have damaged the credibility of the party and the government, and naturally damaged the credibility of the mainstream media under the leadership of the party and government. For example, shortly before a national ministry just rumor oil prices, the mainstream media sound did not break, have begun to increase local. Similarly, a deputy director of the Ministry was reported by the real name, the Ministry spokesman came out to refute rumors, the mainstream media to report, soon after proved that not rumors, but the truth. The phenomenon of credibility of government and the media will have a negative impact.

\subsection{Complicated Opinion Environment}

Our country is in the transition period of reform, but also the social contradictions concentrated outbreak. All kinds of contradictions are complicated, emergencies and malignant events occur frequently, and Chinese society has entered a period of high risk. In the process of the formation of public opinion, there are many complicated factors in participation, game and contest. A variety of social forces involved in public opinion, coupled with new media fueling, in hot spots and unexpected 
events, inevitably rumors, lies flying, noise, noise flooded. Faced with such complex reporting environment, the mainstream media should not only speed up the pace with the new media, but also occupy the commanding heights of the public opinion under the real premise, and the difficulty can be imagined. Over the years the economic income level is not high, the funding gap, in addition to the basic salary of employees, ensure the normal operation of power station outside, can be put into television the money is less and less. The bottleneck of capital restricts the quality of program, and the influence of audience rating on advertising is very important. As a major source of revenue, advertising revenue has fallen, and the overall development of television has fallen into a vicious circle. It is impossible to launch and purchase programs in an innovative way, which directly affects the spread and influence of programs. Digging into the news behind the news, providing ideas and perspectives on facts, may be more useful to the audience. At the same time, this is where the advantages of traditional mainstream media. Unfortunately, some of the traditional mainstream media did not play the advantage of good. When the sound of aphasia, lack of response to the concerns and needs of audience.

\section{Suggestions on Enhancing Transmission and Influence of Mainstream Media}

\subsection{Strengthen Responsibility Sense}

Accident reports, let people realize the great power of micro-blog at the same time, also exposed a concern and pondering: some mainstream media pay homage to micro-blog and other new media, lost in its great power, blindly follow micro-blog set the topic to run, the lack of independent judgment, lack of the guidance of public opinion consciousness, in an irrational state. We should see micro-blog and other new media can set off a far-reaching revolution in communications. It should be standardized. If the mainstream media no judgment followed, these rumors and violence in the media release, amplifying on the traditional channel, the guiding force of harm to society as well as the mainstream media will weaken the immeasurable. So, in the cacophony of new media, the mainstream media should adhere to their own social responsibility for the hot line, the network of public opinion, based on the analysis of calm closely tracking, with the professional standard of objective and rational, constructive value judgments, to restore the truth with exclusive survey, always grasp the correct direction. On the one hand, the hot topics on micro-blog, WeChat, blog and other platforms are discussed, and the related news materials are sorted out and some of them are reported in depth. On the other hand, the mainstream media can spread events extensively through the platform of mainstream media in the process of reporting and investigating a certain event, and increase the discussion with the audience on hot topics. The mainstream media should pay attention to the essence and connotation of news, ensure the timely follow-up of hot events, and maintain the authority of mainstream media. We should also strengthen the news lively discussion board, invited experts and senior commentators' hot news events, using the correct public opinion guiding social experts and scholars and media commentators, and exert influence in the mainstream media.

\subsection{Grab Time Windows}

Compared with the traditional mainstream media, the dissemination of information quickly is one of the biggest advantages of the new media. In the era of everyone has a microphone, the mainstream media to change the passive situation in the timeliness, will take the initiative to learn new communication technology, accelerate integration with the new media competition, the first time to seize the commanding heights of the information, the first time to guide public opinion, to snatch the initiative of leading public opinion. Focusing on service thinking means changing the concept of communication, not the traditional, but constructing a new type of principal factor relationship, especially promoting the development of mainstream community. In the Internet age, the main factor interconnection is greatly enhanced, the social effect is prominent, and the community means word of mouth communication. The audience is the best topic producer and media. For the new mainstream media, the community construction cannot be ignored, the mainstream media represents the 
mainstream audience, only to be the spokesman of the community, can enhance the sense of identity of the network community to the mainstream ideology. Now the media industry has already gone through the end, that is the end of the broadcast publishing stage. In the new media environment of information explosion, the user group needs more customized services than ever before. The new media to the inherent technical advantages for new user needs rapid product iteration, and the traditional media because of lack of short board products thinking and new technology, caused the layout of new media is nothing fundamental. Product iteration is the pursuit of speed, one step ahead, seize the opportunity, otherwise it may cause loss of the audience. Therefore, the breakthrough product iteration the new mainstream media need thinking.

\subsection{Build Brand Columns}

In the huge information field, the audience's selection information has such a mentality: they are more willing to accept the information and views of journalists, commentators and presenters who are accepted by them. At the same time, the news center host package to conduct special research, according to the news anchor, represents a stable atmosphere, the credibility of the professional requirements of their dress, manners, ways of reporting norms and promotion, and strive to build many news commentators and hosts. At present, the star effect has begun to highlight, and their growth and expansion not only make brand programs have obvious logo, but also greatly enhance the media influence. The attraction is the critical path to gain influence. The new mainstream media should be able to win the attraction and integration of resources from. The attraction is the key to identity, to fully consider the audience's psychological and social media habits, the financial media form and mode of operation, integration of resources gathering and communication channels, using the fans to build their own group of social media networks, to enhance the appeal of the content. The service is the inherent requirement of gaining influence. The public service of the media is mainly embodied in the realization of a series of public interests at the core of the public's right to know. In the report of public opinion supervision and emergency, new media because of its low threshold, anonymity, rapid spread characteristics, public services play a more and more important role, in the media convergence trend, new mainstream media using social media, strengthening its public service, to create a more efficient platform to express their opinions and healthy media environment. For users, in the information and media almost everywhere today, only the most appropriate to meet their specific needs of the media to gain their attention, to win their use. The concept comes down to a primary principle of the supremacy of the user experience. We design and develop media products from the perspective of user usage scenarios, and even exceed the user expectations of the use of experience, in order to win the favor of the market.

\section{Conclusion}

The audience is increasingly fragmented, the value is increasingly diversified, the new media is increasingly explosive development, which is the reality of radio and television media environment. In the new historical coordinates of the mainstream media, only under the premise of adhering to social responsibility, active and new media integration, build a platform for all media communication. According to the characteristics of the audience, we carry on the fine processing of news content, enhance the spread of power and influence.

\section{Acknowledgment}

This paper is the periodical results of the University Level Subject of Xi'an Peihua University in 2017 named “Research on Discourse Strategies in Government's Response of Paroxysmal Public Events - Taking Xi'an as an Example” (Grant No. PHKT17077).

\section{References}

[1] Li Zhaocui. Research on Public Opinion Propagation and Early Warning Model of Emergency 
Network [J]. Computer \& Telecommunication, 2016(10): 30-32.

[2] Hou Lei. A Research on the Online Public Opinion Control Mechanism of Emergency in the Big Data Era [J]. Public Administration \& Law, 2016, (10): 67-72.

[3] Wang Xu, Sun Ruiying. Research about Online Public Opinion Spread during Emergencies Based on Social Network Analysis- A Case Study of the Wei Zexi [J]. Information Science, 2017, 35(3): 87-92.

[4] Sun Ruiying, Wang Xu. Empirical Studies of Network Public Opinion Spread during Emergencies [J]. Journal of Modern Information, 2016, 36(12): 65-72+77. 